Forum Kritika: Regional Studies on the Chinese Diaspora in the Philippines

\title{
REGION AND MICROHISTORY: WRITING THE CHINESE DIASPORA IN THE PHILIPPINES
}

\author{
Richard T. Chu \\ University of Massachusetts, Amherst \\ rtchu@history.umass.edu \\ Caroline S. Hau \\ Kyoto University \\ hau@cseas.kyoto-ac.jp
}

THIS SPECIAL SECTION OF KRITIKA KULTURA aims to showcase new studies on the Chinese diaspora in the Philippines. In particular, the three articles deal with "regional" forms of transnationalisms, loosely defined as pertaining to those travels-whether educational, personal, political, economic, or even romantic itineraries-between the Philippines and what is now called "East Asia" (Northeast and Southeast Asia). ${ }^{1}$ By focusing on transnational "Chinese" family histories, they attempt to go beyond the methodological nationalism that treats the "nation/state/ society" as the "natural social and political form of the modern world" (Wimmer and Schiller 301; see also Emmerson 1-21).

Shaped by the exigencies of decolonization, the Cold War, and post-colonial nation-building, earlier accounts and analyses of the history of the diasporic Chinese have been largely confined within the territorially-bounded Philippine colonial and national state. Moreover, their reliance on sociological paradigms of the time have sometimes resulted in a tendency to cast the ethnic identities of these diasporic subjects in binarist, either-or terms, in the interest of subsuming the life stories of these subjects into metanarratives of the Philippine or Chinese national histories.

The popularity of transnational approaches to the study of the Chinese diaspora over the past two decades is part of a broader intellectual critique of the nationstate as a unit of study and action; and as a geopolitical, economic, and cultural system. $^{2}$ By focusing on the dynamic and complex flows, interconnections, and 
exchanges between as well as beyond the Philippines and China, they demonstrate how ethnic/racial categories such as "Chinese" and "Filipino" are constructed, negotiated, contested, resisted, and evaded. ${ }^{3}$

Instead of commemorating or studying events based simply on the lives of Filipinos, giving importance and credence to experiences pertaining to the Philippine Chinese-e.g., the massacre of the Chinese in 1603 and 1639; application of the Chinese Exclusion Act in the Philippines in 1902; the granting of mass naturalization in 1975-points to the recognition of "Tsinoys" as part of Philippine history, a point underscored by the Philippine government declaration of the Chinese Lunar New Year as a special non-working holiday in 2012. Studying ethnic Chinese histories also necessitates the extension of the geographic boundaries of what constitutes Philippine history because these migrants were not bachelors who did not maintain familial ties with people in East/Southeast Asia. (Similarly, to study Philippine history today without giving consideration to the transnational linkages many Filipino families have formed in North America, the Middle East, among others, panders to the nation-bound approach to history that suffers from a myopic and parochial view of the world.)

In his study of the Chinese merchant elites in colonial Manila from the late nineteenth to early twentieth centuries, Andrew Wilson (227) argues that "at the root, to be Chinese in the Philippines, that is, one nationality residing in the space

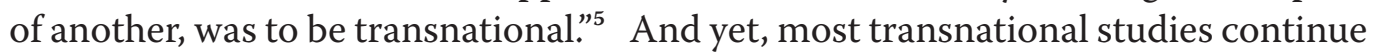
to be unilinear, if not unidirectional, in their focus, dealing, for example, with the relationship of the Chinese to the state(s) in the Philippines and China, or the flows of people from China to the Philippines (and, at most, the return of overseas Chinese to the mainland), or the "contributions" of Philippine Chinese to both Chinese and Philippine national development.

This special section highlights the methodological importance of multi-sited research and multifocal perspectives when examining the transnationality of these Chinese families. Many studies on the Chinese focus mainly (often exclusively) on Chinese experiences and activities in just one locality-i.e., what happened to or what the Chinese did in the Philippines, or what Chinese did in or for China. The articles in this Forum Kritika point to the fact that the subjects under study themselves had multifocal perspectives, not only in the sense that their visions of themselves were crafted out of their location in-and travel between-more than one country, but also in the sense that their exposure to multiple societies, cultures, and viewpoints may have been actually constitutive of their self-identification as "Chinese" and/or "Filipino" and/or "Chinese Filipino"/Tsinoy. The dichotomy between "Chinese" and "Filipino" - an artifact of history, politics, economy, and culture-belies the actual hybridity of these political and cultural signifiers and, even more importantly, overlooks their co-implication in each other and their mutually constitutive relations, the ways in which each term interacted with, and was shaped, by the other. 
This is true, but not always acknowledged, in studies of modern China. Monolithic notions of "China" and "Chinese culture" are now being questioned by the reality of the hybridity of Chineseness (Ong and Nonini 26; Shih 4) as well as "China" itself, a hybridization in which Southeast Asian Chinese and Southeast Asia played a crucial role as agents and site respectively of immigration, activism (Chinese and Southeast Asian nationalism and socialism/communism), economic activity, and modernity (Godley 3; Cook; Duara 39-40). The modernization of China and Chinese culture cannot be understood except in terms of China's embeddedness in the regional system in East Asia. The impact of trade with western powers was, in fact, confined mainly to the coastal regions of China; it was arguably intra-Asian trade rather than trade with the West per se that penetrated the Chinese hinterlands and linked China to the global trade system (Sugihara 2, 8-9). Moreover, modern "Chinese" culture is shaped by the circulation and exchanges of ideas, commodities, and people along the pathways created in the East. The role of religion and missionaries as vectors of the translation of political, economic, and cultural concepts from English, French and Japanese into Chinese (as part of the so-called "translingual practices," as discussed by Lydia Liu) and the rise of the so-called "Anglo-Chinese" (Hau 185-86, 188-89) highlight the regional salience of this cultural hybridization wrought by migration, commerce, cosmopolitanism, and nationalism.

This pattern of region-wide hybridization challenges the conventional periodization of Philippine history that separates the late Spanish from early American periods (Chu, Chinese and Chinese Mestizos 16): in economic terms, the extent of Spanish Philippines' dependence on trade with Great Britain and the United States, mediated by British, American, and Chinese country traders, already provoked Spanish complaints that "from the commercial point of view the Philippines is an Anglo-Chinese colony with a Spanish Flag" (Recur 110, qtd. in Wickberg 280). If the Philippine economy was already linked to American and British economic activities in the region and beyond even before the advent of American colonialism, then the idea of the American period as representing a decisive break with the Spanish era needs to be interrogated.

Complementing broad historical, economic, and sociological studies, the articles in this section adopt a microhistorical perspective in a series of family histories that combine biographical insight with attention to context. Such an approach highlights the multidirectionality of these flows-cultural, financial, or infrastructural-and show how class, gender, and race play important roles in enabling as well as limiting these flows and movements. ${ }^{6}$ Transnationalism (or in the case when referring to the time before the founding of the Philippines and China as nation-states, probably better termed as "transregionalism") in these papers is not a mere abstraction, but concrete and often intimate, lived experience involving individuals and families interacting with larger institutions like schools, churches, organizations, and states, and embedded in local, national, regional, and 
global networks. The papers eschew a one-way sociological narrative of migration, settlement, and assimilation and the contrapuntal narrative of sojourn and return. Instead, they call attention to circulations and returns, multiple identifications rather than stable identities, flexible strategies for dealing with groups and communities and vis-à-vis states, markets, and public spheres. In so doing, they provide insights into the dialectic between "roots" and "routes" (to use James Clifford's terms).

The question of "historical invisibility" poses special challenges for the study of Philippine Chinese, given their economic visibility and might in the face of social marginalization and political disenfranchisement. ${ }^{7}$ For a long time, "Chineseness" remained a cipher in Philippine literary and cultural representations: "Chinese mestizo(ness)" had been largely absent in Philippine literature, which had tended to focus on the Spanish and Spanish mestizo in its representations of elites, even as the "Chinese" figured in Philippine literature as the proverbial "alien" who embodied predatorial capitalism, whether in its comprador colonial or postcolonial businessman-as-corruptor forms. ${ }^{8}$ Microhistories illuminate the nuance and complexities of individual lives, restoring agency to these individuals, while showing how larger forces are at work in the unfolding of individual and collective histories. Microhistories are not simply a way of giving voice or visibility to the Chinese, but of writing back at dominant scholarly and popular representations of the Chinese.

Moreover, as Richard T. Chu shows in "Reconstituting Tsinoy Family Histories," the task of archival research and oral history is itself transnational in the sense that historians need to be able to gain access to a variety of people as well as a variety of sources in a variety of languages and libraries/archival holdings that are geographically spread out both within the Philippines and across the world. ${ }^{9}$ A scholar would have to be able to work in at least five languages or topolectsSpanish, English, Chinese, Hokkien (Minnanhua), Tagalog, Cebuano, Ilocano, a Mindanao language such as Tausug - to build a picture of the so-called Chinese in the Philippines.

Chu's tracing of his own family tree leads him to interrogate the bilateral approach that focuses exclusively on China-Philippines flows and movement, as well as the biological concept of "family" and the monogamist notion of marriage that underpin it. What he shows in his article is the flexibility of the Chinese family, with adoption and polygamy playing roles in its making, and its mobility, with a great-grandfather traveling to Taiwan, and with Richard himself now based in the United States of America. ${ }^{10}$

The two other articles by Josphine M.T. Khu and Teresita Ang See (with inputs from Carmelea Ang See) present richly textured family histories that further illuminate the hybridity, multisited activities, and complex identifications of the Chinese family in, across, and beyond the Philippines.

Josephine M.T. Khu's article recounts the life of a prominent Chinese merchant, José Tan Sunco (Chen Guangchun), who amassed a fortune in the textile business 
(a clear indication of his-and the Philippines'-embeddedness in the intra-Asian as well as global trade system), and used his fortune to build a grand house and acquire substantial chunks of real estate in his native Quanzhou, Fujian Province. One of José Tan Sunco's most important contributions to his hometown in the mainland was his advocacy of education, particularly for girls. A proverbial merchant-patriot, Chen was one of many Southeast Asian Chinese who put their talents, fortunes, resources, ideas, and networks-all nurtured by their long-term stay in Southeast Asia-to good use in order to modernize China, proof enough that Southeast Asian Chinese played an important role in China's modern history. As Khu demonstrates, the China-Philippine connection was not one-sided. For Khu, "the Philippines played a large part in every aspect of the life-business, personal, and philanthropic - of a figure prominent in the local history of one of China's oldest cities." Chen was a "wealthy urbanite with foreign tastes, a wife of mixed heritage, progressive ideas about the education of girls, and a staunch supporter of a representative of a foreign religion." ${ }^{11}$ With their constant travels, extensive business empire, and savvy abilities to engage in flexible and border-crossing practices, Tan Sunco and his contemporaries prefigure the cosmopolitanism of present-day Tsinoy transnationals in the Philippines (see Chu, Chinese and Chinese Mestizos Chapter 3, and Chinese Merchants of Binondo).

In Teresita Ang See's "Navigating Cultures, Forming Identities," readers get an intimate glimpse of Ang See herself as activist, community leader, teacher, scholar, and one of the most celebrated Tsinoys in the contemporary era. At the heart of her story is her indomitable mother, the American-Filipina mestiza Carmen Davenport Barraca Ang. Highly educated, beautiful, and a gifted multilingual, Carmen spent a year in China with her husband's relatives and acquired a Chineselanguage education that gave her a good command of Hokkien. Ang See credits her own "colorful ethnic origins" with "shap[ing her] . . . multiracial, multilingual identity": "We had the support of the Chinese community in terms of scholarships and education, but we also had the support and nurturing from our Filipino mother and some of her relatives." Ang See's richly detailed account underscores the degree to which structural constraints - the lack of access to citizenship being the most important-can hamper a Philippine Chinese's "sense of identification with the Philippines," even as it highlights the "situational identities" that her mother, as well as she and her children, assume in everyday life as they navigate among different linguistic, geographical, and cultural communities. If her children can do so with far more ease than their cousins or than the earlier generation of Tsinoys, it is because Ang See's trenchant critique of ethnocentrism, both Chinese and Filipino, and her inspiring activism helped pave the way for greater public acceptance of the Chinese in the Philippines.

In encouraging the microhistorical approach to the study of the Chinese diaspora in the Philippines, the co-editors of this Forum Kritika section also hope that more attention would be given to the study of marginalized or neglected voices in Tsinoy 
history. For instance, far from being peripheral, women are, as Chu argues (and as the two other essays demonstrate), crucial to broadening our understanding of Philippine history and society. Until the twentieth century, Chinese women remained tied to their local places of birth and marriage in China, and for this reason, they served as proactive agents in the socialization (and even "sinicization") of their male marriage partners (and children) who migrated to Southeast Asia and other parts of the world or commuted between their mainland hometowns and their places of residence or settlement outside China (see Shen). An intriguing detail of Khu's account of Tan Sunco's family history and in Ang See's autobiography casts a revealing light on a relatively understudied phenomenon: the presence in China of mestizo (mixed ancestry) women and children. Tan Sunco's second wife Wei Zhidi, it turns out, was a mestiza who may have been of Filipino or Spanish (or both Filipino and Spanish) ancestry. Ang See's mother Carmen was a half-American, half-Filipino woman who lived in China for a year. ${ }^{12}$ However, even though the patriarchal society in China might have relegated them to a lower status, these mestizo women led interesting and active lives. Ms. Wei was a devout Catholic woman who influenced her husband José in building a girl's school in Quanzhou, with his second daughter Jee Gee running it. By sheer determination and through her linguistic skills, Carmen learned Hokkien quickly and earned the respect of her in-laws. Like their male counterparts, women of Chinese diasporic families were "victim-agents" who found ways to participate in, collude with, and negotiate with attempts of "Others" to control them (Chinese and Chinese Mestizos 413). ${ }^{13}$

Overall, the co-editors hope that the essays will motivate readers to reconstitute Tsinoy life stories or family histories that would help deepen and widen our knowledge of Philippine history; interrogate relations of power; and inspire others to work for change.

\section{Notes}

1. Interpreted another way, "regional" can also pertain to studies focusing on different regions outside of Manila. Several works have already been published that go beyond a "Manila-centric" focus of studying Tsinoy individuals, families, and communities (see, e.g., Omohundro; Dannhaeuser; Reynolds and Reynolds; and Ang See). Too, "regional" can pertain to the flows and interconnections between the Philippines and other parts of the world, not just Southeast/East Asia, such as the Philippines and Spain; the Philippines and Mexico; and the Philippines and the United States.

2. See, for example, Ong and Nonini; Lok; McKeown; and Hsu for how such approaches have been used in the study of different Chinese diasporic communities around the world. 
3. For a stringent critique of scholarship on Chinese in the Philippines, see Wilson 15-26. On the flexibility of Chinese and Chinese mestizo identities among the elites in the Philippines during the late Spanish and the American and Commonwealth period, see Chu, Chinese and Chinese Mestizos. Both Wilson and $\mathrm{Chu}$ also call for new periodizations in the study of the Philippine Chinese.

4. "Tsinoy" (derived from "Tsino" and "Pinoy") is a term coined in the 1980 os by Kaisa Para sa Kaunlaran, Inc., to refer to "Chinese Filipinos" who are politically and socially integrated into Philippine society. "Chinese Filipino" is often distinguished from "Filipino Chinese" in terms of generation, with the latter denoting first-generation migrants who are non-Philippine citizens, a distinction that is also echoed in the difference between "Chinese Overseas" and "Overseas Chinese." "Ethnic Chinese" is generally used to refer to self-identified "Chinese" and their descendants outside China, Taiwan, and Hong Kong, regardless of their citizenship status. The term "Chinese diaspora"-while not without its critics-calls attention to the flows, linkages, and connections established between "China" (not only in its statist sense, but, in many cases, its cultural, civilizational, and symbolic senses) and migrants and their descendants from the age of regional commerce, to the age of maritime exploration through the age of imperialism, and now globalization.

5. Wilson qualifies his assertions about "transnationalism" thus (227): "These transnational linkages were for the most part confined to a shallow ninety-mile band of the Southern Fujian coast at one end and central Luzon at the other. Therefore, to call these networks transnational, without remaining aware of the inherent local character of migration, is to run the risk of imputing to discrete linkages a degree of historical import that these natural and mundane exchanges of talent, wealth and information did not hold for their practitioners. During the period from the 1880 os to the 1910 s, and for many years after, the key ties were translocal more than transnational... . Yet at the same time, to ignore the impact that these mundane exchanges of wealth, talent, and information had on larger historical trends, for example, in facilitating the commercialization of Philippine agricultural export economy and with it a socioeconomic revolution in the islands, would be equally myopic." It should be noted, however, that while the Chinese merchants Wilson was studying moved within this "ninety-mile band," other studies, especially those focusing on individual or family histories, indicate that many other diasporic Chinese during this period also had links to places such as Taiwan, Vietnam, and other Southeast Asian countries; to other cities in China like Beijing, Shanghai, Macau, and Hong Kong; and in the Philippines like Cebu, Iloilo, or Sulu (see for instance, Chu, Chinese and Chinese Mestizos; de la Cruz, Jr.).

6. On microhistory and its approach to local history and emphasis on domestic affairs and biographies of the obscure, women, family and village, see Ginzburg. For comparisons, see Bao's multi-sited research on the role of gender, sexuality, and class in the formation of Chinese Thai identities in Bangkok and San Francisco.

7. We thank the anonymous reviewer for encouraging us to elaborate this point. 
8. Two notable exceptions are Ninotchka Rosca's State of War and F. Sionil Jose's Sherds for their nuanced treatment of the issues of Chinese mestizoness and Chineseness in the Philippines.

9. See also Fung's family chronicles of the Lichaucos.

10. Charlson Ong's Centennial-prize-winning novel, An Embarrassment of Riches, is noteworthy for locating its discussion of the Chinese Filipino within a specifically Nanyang imaginary.

11. While the idea of Chinese "influence" on Philippine culture is now quite orthodox, systematic study of the impact of Chinese migrants' Southeast Asian experiences-taking the form of material culture (food, clothing, commodities), language, pathways in the circulation of ideas, practices-on Chinese culture, particularly in Southern China (huanan) remains to be done.

12. Wealthy Chinese merchants most probably carried out this practice of bringing their mestizo wives (and children) to China. Spanish missionaries in China disapproved of this practice, reporting that most of these women were concubines who were sometimes treated as slaves (see Chu, Chinese and Chinese Mestizos 173-4).

13. A document found in the Bureau of Insular Affairs at the National Archives and Records Administration in College Park, Maryland, USA reports that hundreds of "Filipino" women in the 1920 s "invaded" the U.S. consulate in Amoy to "(demand) protection from the cruelty of their husbands, who also have Chinese wives in China" (qtd. in Chu, Chinese and Chinese Mestizos 361). 